\title{
A geração Y e sua influência nas organizações
}

\author{
Generation $Y$ and its influence in Organizations \\ Flavio Tavares de Almeida, Deise Soares da Silva Tavares, Fátima Niemeyer da Rocha, Adriana \\ Vasconcelos da Silva Bernardino.
}

\begin{abstract}
Resumo
Este estudo tem por objetivo analisar os aspectos comportamentais da geração Y e sua influência no contexto organizacional. O contexto social é considerado, pois o meio irá atuar como norteador das atitudes dos representantes dessa geração, fazendo-se necessário o entendimento sobre suas interferências. Busca, também, compreender as interferências culturais, as atitudes e os comportamentos dessa geração, pois a significação que as pessoas dão ao trabalho estará ligada às suas formas de representação, o que acaba por nortear suas ações no meio organizacional. O trabalho, por sua vez, também irá exercer interferências em sua forma de agir e ser, produzindo singularidade e contribuindo para a formação da base de sua identidade profissional.
\end{abstract}

Tavares DSS, Rocha FN, Bernardino AVS. A geração $\mathrm{Y}$ e sua influência nas organizações. Revista Mosaico. 2013 Jul./Dez:; $04 \quad$ (2): 31-43.

Palavras-chave: Geração Y. Trabalho. Organizações.

\begin{abstract}
This study aims to analyze the behavioral aspects of generation $\mathrm{Y}$ and their influence on organizational context. The social context is considered, because the Middle will act as guide of the attitudes of representatives of this generation, making necessary the understanding about their interference. Search, too, understand the cultural interference, the attitudes and behaviors of this generation, because the meaning that people give to work will be linked to their forms of representation, which ultimately govern their actions in the middle. The work, in turn, will also exercise interference in their way of acting and being, producing and contributing to the formation of the basis of their professional identity.

Keywords: Generation Y. Work. Organizations.
\end{abstract}

\section{Introdução}

Inicialmente, entendido como algo que trazia dor e sofrimento, o trabalho, ao longo da história, teve evoluções significativas e, hoje, é buscado pelos indivíduos não somente para sua sobrevivência, mas também para afirmação de sua identidade, autorrealização e desenvolvimento, proporcionando uma sensação de completude à medida que sua relação é promovida. No contexto do trabalho, o estudo sobre as Gerações teve inicio a partir da revolução industrial, com a necessidade de se compreender a formação da subjetividade das pessoas, e vem se desenvolvendo, com maior ênfase, na modernidade, levando a acaloradas discussões entre os gestores nas empresas.

Nas organizações, a geração Y tem sido fonte de muitos conflitos, por diferir, e muito, das outras gerações, em seus comportamentos e necessidades. Essa geração, quando ingressa no mercado de trabalho, traz consigo uma infinidade de expectativas e desejos que faz com que, de inicio, tenha um envolvimento maior com o trabalho, mas que, com o passar do tempo, se as forças que impelem sua ação não forem estimuladas através da satisfação de suas necessidades, tendem a causar baixa produtividade e defasagem de mão de obra.

Assim, o presente estudo aborda a conceituação de trabalho e suas influências na vida das pessoas, apresenta os aspectos mais significativos e relevantes da evolução do trabalho que tiveram maior impacto sobre a história, estabelece relações com as etapas vivenciadas por cada geração, além de demonstrar o que as empresas esperam de seus funcionários após a globalização e o que isso traz como consequência aos indivíduos. Além disso, aborda o conceito de gerações no trabalho, como surgiu e quais são as gerações presentes atualmente no contexto organizacional; de forma sucinta, ressalta o que se modificou em cada uma delas e como se comportam no ambiente de trabalho. Focalizando de forma mais aprofundada a geração $\mathrm{Y}$, o estudo busca um maior entendimento sobre sua conduta nos contextos social e organizacional e sobre suas posturas, vistas pelas organizações como difíceis de gerenciar, e descreve 
suas expectativas em relação às empresas.

\section{O Conceito de Trabalho}

Para o levantamento das necessidades da geração Y frente ao mercado de trabalho, no sentido de se encontrar alternativas de como lidar com esta geração e possibilitar seu entendimento, é necessário que se compreenda a representação do trabalho e de seus aspectos motivacionais na vida das pessoas, pois à medida que sua interação é promovida ocorre a formação de novas modificações e arranjos existenciais, assim como sua evolução no tempo, as etapas de suas transformações, além das expectativas e exigências tanto das empresas quanto dos seus funcionários em relação ao mercado globalizado.

Segundo Carmo (2010 apud Macedo, 1997, p.16), a palavra 'trabalho' tem origem no latim, na palavra tripalium, que era um "instrumento formado por três estacas para manter presos bois ou cavalos difíceis de ferrar; (...) pena ou servidão do homem à natureza". Do sentido de esforço para a sobrevivência, o trabalho transformou-se em produtividade e ocupação. Um esforço humano que implica sacrifício e dor, moléstia e sofrimento, e que determina a produção ou conservação de um bem ou de uma utilidade. O trabalho era lembrado como algo que trazia sofrimento, mas ao longo do curso da história modificou-se e transformouse em algo próspero. $\mathrm{O}$ trabalho pode ser entendido como uma atividade complexa, mas que não dispensa o jargão de que este seja um mal necessário, porque não só garante a sobrevivência, mas também promove interação e desenvolvimento, tendo seu valor pessoal, psicológico e social. A vida pode não se resumir em trabalho, mas sem ele, pode não existir vida no sentido desses valores, uma vez que este é elemento estruturante da vida humana e representa também responsabilidade em desenvolver "o potencial humano" e a "afirmação da própria identidade" (Novo et al, 2008, p.100). No sentido ontológico (Ciência e Profissão, 2007, p.24), o trabalho é considerado como algo que, à medida que vai tendo sentido de produtividade, também vai dando forma a seu sentido de "conotação existencial", fazendo com que as pessoas se sintam socialmente incluídas e reconhecidas pessoalmente, criando uma relação de interdependência com o trabalho.

A sociedade atribui forte valor ao trabalho, o colocando como algo fundamental e necessário, podendo se mostrar contrária a atitudes que não $o$ contenham como objetivo. O ser humano atribui significados psíquicos e sociais ao trabalho, advindos de sua interação com o meio, que acaba por nortear seu modo de pensar e agir. Seu fracasso ou sucesso também depende desta interação, pois à medida que essa é solicitada o ser humano sofre modificações e consegue perceber-se incompleto e dependente do reconhecimento das pessoas. Novo et al (2008, p.100) afirma, nesse sentido, que não podemos deixar de reconhecer a crescente importância das organizações voltadas para o trabalho na vida dos indivíduos, não só como fator de sua manutenção financeira, mas sobretudo, de autorrealização e de autoexpressão.

Para Zanelli et al (2004, p.302), “(...) o trabalhador satisfeito com seu trabalho pode se tornar uma pessoa com mais possibilidades de ser um cidadão integrado a sociedade, a sua família e apresentar melhores índices de bem-estar físico e mental". Isso demonstra o quanto as condições de trabalho em que o sujeito está inserido pode influenciar seu ambiente familiar e social.

\section{Motivação e Trabalho}

De acordo com Spector (2010, p. 284), a "motivação é geralmente descrita como um estado interior que induz uma pessoa assumir determinados tipos de comportamento". E é definida, de acordo com Novo et al (2008, p.103), "como o processo responsável pela intensidade, direção e persistência dos esforços".

O foco que cada pessoa dará a determinada atividade, para que sua meta seja atingida, dependerá do grau de interesse em desenvolver tal tarefa, que, para Spector (2010), pode variar de acordo com sua direção, intensidade e persistência. A direção é a escolha dentro de uma gama de possibilidades, permitindo-lhe optar pela melhor forma de desenvolver tal atividade; a intensidade representa o quanto de esforço despenderá para realização da atividade; e a persistência, consiste em se manter perseverante na obtenção da tarefa mesmo ao longo do tempo. As pessoas realmente motivadas tendem a se manter persistentes na realização das atividades até que sua tarefa seja concluída por completo. Aplicando esse conceito para a geração Y, ao seu comportamento no contexto organizacional, estes jovens sabem o que devem fazer, mas em muitos casos necessitam de direção em meio a tantas alternativas, não tendo dúvidas de que fazem as coisas com muita intensidade, mas em contrapartida, sua persistência não é duradoura.

Conforme Novo et al (2008, p.103), “o fenômeno motivacional é algo complexo e sua compreensão tem sido objeto de diferentes abordagens teóricas". $\mathrm{O}$ tema motivação tem despertado o interesse de muitas organizações e gerado inúmeras pesquisas e investimentos na área, pois alguns gestores entendem que ela seja capaz de melhorar o desempenho de seus funcionários e aumentar a lucratividade da empresa, garantindo maior produtividade. Acreditando nisso, criou-se a idéia de que funcionários motivados apresentam maior desenvolvimento em relação aos outros; e que algo contrário a isso tende a desencadear 
um desenvolvimento não satisfatório e acabar por gerar frustração, estresse e conflitos.

Mas para que não se tenha ideias errôneas em relação à motivação, diante de sua complexidade, deve-se levar em consideração que esta pode se dar de forma passageira; é importante que se compreenda que não é algo aprendido, pois pertence à ordem da subjetividade, variando de acordo com o grau de interesse e necessidades aplicados de forma individual. De acordo com Novo et al (2008, p.103), "produtividade e motivação não dependem somente de incentivos externos, mas da interação entre individuo e organização: de um lado, os objetivos da organização; do outro, os objetivos das pessoas, isto é, o que elas buscam e esperam do trabalho". Portanto, devem-se encontrar formas que unam os interesses das organizações aos de seus funcionários, buscando alternativas através de conhecimento técnico e cientifico ou experiências vivenciadas por outras pessoas e organizações, que possam servir como norteadoras nesse processo.

\section{Evolução Histórica do Trabalho}

Pode-se falar de trabalho, segundo Zanelli et al (2004, p.28),

desde os primórdios da humanidade: com as comunidades de caçadores e coletores 8.000 anos a.C., a incipiente agricultura no Oriente Médio, China, Índia e norte da África, o trabalho escravo nas civilizações antigas e a relação servil na Idade Média como alguns exemplos.

Uma das primeiras formas de demonstração de trabalho que passou a envolver o grupo na obtenção de um resultado comum foi apresentada por Macedo (2010, p.2), com o exemplo dos nômades, os quais tinham a "possibilidade de ter acesso ao consumo organizado de uma série de bens que melhoravam suas vidas. No princípio, eles trabalhavam por conta própria e viviam basicamente da caça e da coleta", precisando migrar quando estes alimentos acabavam, pois não contavam com outras formas de sobrevivência. Mas ao conhecerem a agricultura e a domesticação dos animais, que traziam o alimento para próximo deles, sem que precisassem se mudar para isso,

se transformaram em sedentários e precisaram de ajuda para executar alguns tipos de atividades que não podiam realizar sozinhos, principalmente a agricultura e a pecuária. Formando-se as tribos, onde as pessoas dividiam suas tarefas em um regime de cooperação. (Macedo, 2010, p.2)

Com a queda do império romano, durante a Idade Média, conforme descrito por Macedo (2010), surge o feudalismo, onde já não se tinha mais o predomínio do trabalho escravo, mas sim o trabalho servil, e trocavase a mão de obra dos trabalhadores por moradia e alimentação, funcionando como meio de subsistência. $\mathrm{O}$ poder ainda centrava-se aos senhores feudais. De acordo com Oliveira (2002), no Brasil, isso não foi muito diferente, porque, de inicio, também se tinha o predomínio da escravatura, com a sobrevivencia focada na agricultura. $\mathrm{O}$ nosso país teve sua abolição em 1888, mas sem ter, ainda, os direitos trabalhistas assegurados aos trabalhadores. A abolição provocou a queda da monarquia, que precisava do trabalho escravo para se manter. Outro período que teve o trabalho como marco foi a Era de Vargas, que trouxe o crescimento da industrilização no Brasil e levou a criação de leis para a regulamentação do trabalho, garantindo os direitos e deveres dos trabalhadores.

De suma importância na história do trabalho, que marcou os países de um modo geral, foi o período logo após as duas guerras mundiais - que presenciou o surgimento da geração belle époque -, marcado pelo o inicio da inserção das máquinas no trabalho, a revolução industrial, tornando a produção mais rápida e não mais manufaturada. Neste período, segundo Novo et al (2008), o mundo foi passando por inúmeras transformações econômicas, mas também sociais e tecnológicas, provocando modificações de um modo geral. Nessa perspectiva, Chiavenato $(2010 \mathrm{~b}$, p.34) propõe uma divisão da história do trabalho em eras, cada qual englobando as transformações econômicas ocorridas, em etapas, ao longo do século XX até a atualidade. O autor descrimina três eras: "Era industrial clássica; Era industrial neoclássica e Era da informação".

A era industrial clássica, consiste "no período logo após a revolução industrial e que se estendeu até meados 1950" (Chiavenato, 2010b, p.34); foi um período marcado por crises, embora com prosperidade, quando ocorreram mudanças, ainda que vagarosas, e teve como características a ampliação e a intensificação da industrialização mundial, resultando no surgimento de países industrializados. Nesse período, as decisões organizacionais eram muito centralizadas e a hierarquia estabelecida de forma rígida; as pessoas com cargos mais elevados não tinham nenhum contato com os de cargos mais baixos, não se tinha autonomia e a cultura organizacional era, em geral, tradicionalista, numa estrutura em forma de pirâmide. Quando as pessoas eram contratadas para desempenhar tais funções, estas se davam de forma simples e muito limitada. $\mathrm{O}$ ambiente não era algo desafiador e não exigia muitas mudanças, pois ainda não existia muita competitividade em relação ao mercado. A geração que mais presenciou este modelo foi a geração baby boomers.

A era da industrialização neoclássica, segundo Chiavenato (2010b, p.36), pertence ao "período que se estende entre as décadas de 1950 a 1990, tendo seu início após a Segunda Guerra Mundial". Esta era substituiu a anterior, quando o mercado ganhou força e intensidade, mostrando-se mais concorrente e passível de mudanças, 
saindo de uma visão local e regional para chegar aos limites internacionais. Em função dessas mudanças e para acompanhar o mercado que começava a se mostrar mais exigente, as estruturas organizacionais também teriam que sofrer modificações, visto que o modelo anterior já não estava mais apresentando resultados. Portanto, as organizações tiveram que adotar “(...) novos modelos estruturais para incentivar a inovação e o ajustamento às mutáveis condições externas"; adotaram um modelo de "estrutura matricial", na tentativa de derrubar o anterior, o "modelo burocrático", conseguindo promover algumas melhorias, apesar do antigo ainda estar enraizado. Com isso, muitas das grandes organizações se transformaram em unidades estratégicas, para "torná-las mais bem administradas, mais ágeis e mais próximas do mercado e do cliente" (p.36-37). As relações no interior da organização já se davam de forma mais flexível e menos autoritária, mas gerava maior instabilidade e possibilidades de mudanças, exigindo dos funcionários, de forma moderada, um maior conhecimento científico e tecnológico, além da capacidade de se adaptarem a mudanças. Nesta época, também ocorre o surgimento do setor de recursos humanos nas organizações. A geração que mais presenciou este modelo foi a geração X.

E a era da informação, segundo Chiavenato (2010b), tem início na década de 1990 até a atualidade. Essa era também surge a partir da anterior, com as transformações ainda mais potencializadas, pois as informações tornaram-se mais rápidas e sucessivas, com mudanças e imprevistos, sendo sua economia, agora, voltada para o mercado global. O que predomina nesta época é a tecnologia da informação em interação com outros meios de comunicação, diminuindo as fronteiras globais e predominando a agilidade; trazendo, com isso, uma competitividade exacerbada, não só quanto aos membros das empresas, mas também entre as organizações. Nessa época, também surge o conceito de gestão de pessoas nas organizações, que faz com que os indivíduos nelas inseridos sejam vistos como seus parceiros, dando maior liberdade à tomada de decisões na execução de suas atividades para alcançar suas metas e mostrar resultados. Também se passou a verificar as necessidades e expectativas, assim como se importar com a motivação das pessoas. A geração que presencia este modelo é a geração Y. O

emprego passou a migrar do setor industrial para o setor de serviço, o trabalho manual substituído pelo trabalho mental, indicando o caminho para uma era da pós-industrialização baseada no conhecimento e no setor terciário" (Chiavenato, 2010b, p.38).

Assim, devido às transformações ocorridas no trabalho ao longo da história, surge o conceito de emprego, diferenciando-o do trabalho. O trabalho é o esforço humano dotado de um propósito e envolve transformação da natureza; já o emprego é a relação estável e mais ou menos duradoura, que existe entre quem organiza o trabalho e quem realiza o trabalho, dando abertura às empresas para contratarem mão de obra especializada e pagar por isso, sem que necessariamente façam parte de seu quadro de funcionários.

\section{Trabalho, Globalização e Qualificação}

De acordo com Oliveira (2002), em toda história do trabalho, nunca se viu tantas atividades e exigências de conteúdos profissionais se modificarem com tanta rapidez como na contemporaneidade. Com a evolução do trabalho, as pessoas que antes executavam tarefas rotineiras e especializadas, demandando maior número de funcionários para sua execução, hoje estão sendo substituídas por frentes de trabalhos multidisciplinares que participam ativamente das decisões do grupo, sem precisar de muitas pessoas para isso. Este processo obriga as pessoas a se manterem na busca constante por conhecimento, pois se não se estiverem, pelo menos, no mesmo nível que o mercado, atendendo às suas exigências, estarão fora desse meio.

Para Chiavenato (2010b), com a globalização a concorrência aumentou, provocando uma maior competitividade. As empresas também passam por este processo, onde o que conta hoje é sua capacidade de mudança e a forma como respondem à concorrência, tendo que ter capacidade de inovação, agilidade e flexibilidade. Para que isso seja possível, é importante que também busquem por estas qualificações nas pessoas, exigindo, assim, que possuam características de nível cada vez mais elevado. As pessoas estão tendo que se especializar e buscar diferencial em relação às outras, para conseguirem os melhores cargos e salários, pois estes estão sendo ocupados não somente por quem tem mais estudo, mas também por quem tem maior experiência e características cognitivas e comportamentais superiores. O mercado tem obrigado as pessoas a se tornarem cada vez mais especializadas e as que possuem esse diferencial têm mais chances - isso permite às empresas optarem por aquelas que atendam às suas necessidades.

\section{O que as Empresas esperam das Pessoas em Relação ao Trabalho Globalizado}

Segundo Oliveira, (2002, p.78) "diferentemente das épocas anteriores, as empresas, motivadas pela globalização, estão buscando nos jovens outros valores sociais, psicológicos e culturais". Mesmo que as organizações possuam recursos próprios, existem características e expectativas em suas exigências profissionais que são similares umas as outras, que, de acordo com Chiavenato (2010a, p.32-33), são: "foco na missão organizacional", que consiste em conhecer o 
papel da organização em seu âmbito social e ambiental e, assim, poder contribuir para realização de suas metas; "foco na visão de futuro", que considera que conheçam seus objetivos e visão, contribuindo de forma eficaz para seu futuro; "foco do cliente", que enfatiza a satisfação do cliente, atendendo às suas necessidades; "foco em melhoria e desenvolvimento contínuo", que aborda uma postura crítica que possibilita mudanças para sua melhoria, buscando perfeição e aumento do seu valor de capital; "foco no trabalho participativo em equipe", que evidencia que as equipes consigam unir conhecimentos, promovendo o envolvimento de todos, e multiplicar talentos e competências; "comprometimento e dedicação", pois esperam compromisso e dedicação dos seus colaboradores e que forneçam o que têm de melhor, independente do tempo que permaneçam nas empresas; "talento, habilidades e competências", consideradas razão fundamental que orienta as empresas em suas contratações, pois almejam que seus funcionários disponham do melhor talento do mercado e tenham competência para realizar as atividades com muita habilidade; "aprendizado e crescimento profissional", que exige que seu pessoal não fique estagnado, que busque um aprendizado constante e seu crescimento profissional, para conseguir se adaptar ao mundo dos negócios, trazendo prosperidade para a empresa; e "ética e responsabilidade", esperando que realizem suas atividades com seriedade e responsabilidade, pautados no código de ética e na responsabilidade solidária.

Além destas características, as empresas também estão buscando por profissionais, que, segundo Oliveira (2002), não disponham somente de conhecimentos técnicos e científicos, mas que também sejam fluentes em outros idiomas, tenham conhecimento de informática avançado e pratiquem a empatia no ambiente empresarial, sabendo, principalmente, se planejar e se organizar. O desejo das organizações é que tudo isso venha em um único profissional, o que se torna seu grande desafio, pois nem sempre sua busca é satisfatória ou surte resultado, sendo obrigadas, em alguns casos, a encontrar alternativas de indução por meio do oferecimento de recursos e de incentivos.

\section{O Conceito de Gerações}

A partir da revolução industrial, começou-se a pensar as indústrias na forma de organizações, pois o seu desenvolvimento já não estava mais apresentando o progresso desejável para aquele momento. A partir desse novo conceito, passou-se a dar mais atenção ao comportamento organizacional que, segundo Chiavenatto (2010a, p.6), caracterizava-se pelo "estudo de indivíduos e grupos atuando em organizações", com o objetivo de estudar o que cada um poderia oferecer a essas e vice-versa, envolvendo trocas e relações com o meio, pois a forma como se lida com o ambiente faz diferença em seus resultados. Ainda para Chiavenatto (2010a), o comportamento organizacional sofre a influência de fatores de ordem individual e grupal, a partir de constantes trocas com o meio, no qual se compartilha características como: o modo de percepção das múltiplas situações, os valores e a aprendizagem, que, dentro do grupo, abrangem influências de um modo geral, fazendo com que surjam outros fatores que mobilizam a todos, conseguindo o cumprimento das normas e o desempenho dos papéis designados de forma a contribuir para o envolvimento e o desenvolvimento.

Dentro das organizações existem pessoas que interagem o tempo todo e que possuem características, valores, opiniões e conceitos muito diferentes. A época em que as pessoas nasceram, como foram criadas, como foram influenciadas e motivadas, a forma com que lidam com a tecnologia, seu grau de maleabilidade e os fatos e ambientes com que puderam ter contato também fazem a diferença ao se estudar as características de um grupo. Isso, muitas vezes, gera conflitos, pois algumas pessoas podem apresentar características muito distintas e terem desenvolvimentos cognitivos muito diferentes. Partindo dessas observações é que se começou a pensar em uma forma de agrupamento para o entendimento da totalidade, afim de que se pudesse levar em consideração essas diferenças e encontrar fatores predominantes que pudessem nortear o entendimento e o desenvolvimento das pessoas no contexto organizacional. Conforme Oliveira (2010a), essa necessidade de entendimento da totalidade não seria possível sem que se fizesse uma classificação, pois estudar a todos de forma distinta seria praticamente impossível, surgindo, daí, o conceito de gerações.

De acordo com Oliveira (2009, p.40), "o conceito de gerações reconhecido e aceito pela sociedade moderna estabelece o período de vinte anos como marco de separação das gerações", pois é justamente nessa idade que os jovens começam a fazer escolhas no meio social, participando de forma ativa e causando interferência. Segundo Wada e Carneiro (2010), atualmente, temse o conhecimento de quatro gerações distintas que interagem, não somente no contexto familiar, mas, também, no organizacional, sendo comum vermos pessoas com idade de se aposentar ainda trabalhando. As diferenças que cada geração traz, de acordo com o momento em que viveram, são perceptíveis e eminentes quando se relacionam com indivíduos de outras épocas e conceitos. Entre as gerações podem ocorrer dificuldades de interação, devido a diferirem em suas preferências, necessidades e valores. O interesse de um jovem em adquirir tecnologia, por exemplo, pode não ser o mesmo de uma pessoa de geração anterior, que não está acostumada a lidar ou não gosta ou não se adaptou a novas tecnologias. Também Khoury $(2009$, p.122) afirma que "nós podemos sofrer grandes influências de 
diferentes gerações e, consequentemente, isso influencia os nossos comportamentos". Não é porque uma pessoa pertence a uma geração especifica que ela não possa apresentar características diferentes dessa e nem se adaptar ou se modificar em função da interação com as outras.

Dessa forma, torna-se relevante compreender as características das diferentes gerações, que são, segundo Oliveira (2010): Belle Époque, Baby Boomers, $\mathrm{X}$ e $\mathrm{Y}$, suas diferenças e como cada uma reage nos meios social e organizacional, dado que influenciaram as organizações e continuam influenciando nos dias de hoje.

\section{A Geração Belle Époque}

No parecer de Oliveira (2009), a geração Belle Époque compreende as pessoas nascidas entre 1920 e 1940, que viveram entre o momento de transição do cinema, da literatura e da arte e o momento marcado pela crise econômica advinda da Primeira Guerra Mundial. A geração Belle Époque viveu a intolerância política, com poucas alternativas de desenvolvimento e crescimento, além de sofrer com a imigração, como forma de fuga do que a guerra trazia e suas consequências. Devido aos poucos estímulos e perspectivas de vida, aos jovens dessa geração restava trabalhar na carreira militar ou como operários nas indústrias. A vida militar trazia, principalmente aos de classes mais baixas, certo fascínio. Consequentemente, a motivação para a satisfação de suas necessidades ia desde as de ordens mais básicas - como a satisfação de suas necessidades corporais, de segurança (não precisando viver com medo e sob recolhimento social) e de estima (ganhando o respeito e admiração de todos, sendo vistos como heróis ao invés de rebeldes) -, até as de autorrealização (lhes proporcionando crescimento e realização de seu potencial).

Ao vivenciar, no contexto da época, experiências de vida desastrosas e dolorosas, como as catástrofes, crises, separação e destruição de famílias e lares, os membros dessa geração desenvolveram sentimentos e valores que influenciaram toda a sua vida adulta. Apresentavam mais compaixão pelo próximo, mostrando-se mais dispostos a ajudar e reconstruir a sociedade, tanto em sua forma física quanto psíquica, dando valor, principalmente, à família, resgatando laços e priorizando os bons costumes, tanto em casa quanto no trabalho. Eram pessoas altamente tradicionalistas, no que dizia respeito, especialmente, às suas famílias. O líder da casa era sempre o pai; a mãe tinha o papel de cuidadora; e aos filhos, cabia se empenharem nos estudos - cada um desempenhava um papel importante nessa constituição, de modo que não pudessem ocorrer desvios (Oliveira, 2010).
$\mathrm{Na}$ relação com o trabalho, a geração Belle Époque, conforme descrito por Oliveira (2010), se mostra muito dedicada, fiel à instituição, não contesta regras e as cumpre sem hesitar. Respeita a todos, inclusive a hierarquia estabelecida. O importante, para os membros dessa geração, era começar a trabalhar, fazendo uma aliança forte com a organização, quase um "casamento", tendo como meta a aposentadoria. Foi uma geração paciente, que conseguia esperar as coisas acontecerem, pois trazia consigo a ideia de que o sacrifício seria a porta de alcance da estabilidade. Os chefes das organizações que viveram sob o regime militar também mantinham uma postura rígida e autoritária com seus funcionários, pois acreditavam que eles precisavam de alguém com essas características que pudessem conduzi-los ao alcance de seus objetivos. Isso, na época, não era visto como um problema, exemplificado nas palavras de Macedo et al (2007, p.112-113): o "poder somente será exercido se seu detentor for aceito e tiver a capacidade de exercer influência sobre indivíduos, grupos e situações". Essa geração fez surgir o que Oliveira (2009, p.49) denomina “"Anos Dourados', durante os quais a disciplina, a honra, o respeito e a organização definiam todos os comportamentos na sociedade."

\section{A Geração Baby Boomers}

Segundo Oliveira (2009, p.49), a geração Baby Boomers compreende os nascidos entre 1940 e 1960. Eles receberam esse nome após a Segunda Guerra Mundial, na qual ocorreu a explosão de duas bombas atômicas. $\mathrm{Na}$ época, ocorreu um grande número de nascimentos, o que contribuiu para um aumento rápido e significativo da taxa de natalidade em todo o mundo. No pós-guerra, a economia de grande parte dos países sofreu grandes modificações, o que também explica, até certo ponto, o aumento do número de nascimentos, pois se acreditava que isso, juntamente com o esforço de criação de uma sociedade melhor, proporcionaria aos jovens melhor qualidade de vida e de oportunidades, diferentemente da época em que viveram seus pais.

A educação recebida pelos jovens dessa geração seguia padrões vindos de gerações anteriores, como a Belle Époque, baseada na rigidez e nas regras dos campos de batalhas, com duros padrões e intolerância a contestações, delitos e desvios. Atitudes e comportamentos que fugissem ao modelo estabelecido ocasionava duras punições e severos castigos, os quais não se aplicavam somente no ambiente familiar, mas também no trabalho, nos estudos e até no vestuário. Aos poucos, esses jovens foram se rebelando contra a opressão, a política e a educação, apesar de alguns não se incomodarem com isso e, não só aceitarem, como também encararem como uma forma de obter vantagens e conseguir melhores oportunidades. Os das classes mais 
altas foram os mais reivindicadores e contestadores, por perceberem a possibilidade de tomar suas decisões, sem que suas escolhas thes fossem impostas e sem se preocupar com o futuro.

Devido a divergências quanto à forma de enfrentamentodassituações, ocomportamentodosjovens da geração Baby Boomers foi dividido em duas vertentes: "os rebeldes e os disciplinados" (Oliveira, 2009, p.51). Os disciplinados foram os criados por pais trabalhadores e militares; assimilaram com mais facilidade a educação recebida, a aceitaram e fizeram o que deveria ser feito. Sabiam que, para terem suas necessidades satisfeitas em todas as fases, teriam que manter um comportamento aceito pela sociedade, principalmente, aprovado pelos mais velhos. Com valores enraizados, conseguiam obter sucesso, respeito e admiração, tanto no contexto familiar quanto organizacional, sendo vistos como pessoas de comportamentos e caráter a serem seguidos, com capacidade para estar em cargos mais elevados e dispondo de todos os requisitos para a liderança. Devido ao excesso de responsabilidades e de rigidez, os jovens dessa geração tiveram um desenvolvimento cognitivo e psíquico maior e mais rápido que os demais e um censo de responsabilidade mais aguçado, muitas vezes muito precoce, como, por exemplo, no caso da construção de uma família. Já os rebeldes foram o grupo de jovens que não aceitaram muito bem a repressão da educação recebida de seus pais, moldada na educação militar. Pertencentes a famílias com condições financeiras, geralmente, mais altas e filhos de pais militares, suas necessidades básicas já estavam satisfeitas e, por isso, tinham outras motivações naquele momento, o que fez surgir as primeiras formas de contestação cultural/ social/política, com referência ao conceito de gerações.

Conforme Chiavenato (2010b, p.110), "uma necessidade pode ser satisfeita, frustrada (quando a satisfaçãoé impedida) ou compensada", podendo resultar diferentes reações, dependendo de como o sujeito lida com a necessidade e a tensão surgidas em função da frustração. Uma das formas de demonstrar o que sentiam e queriam, "para apresentarem suas transgressões e insatisfações com a realidade em que estavam vivendo" (Oliveira, 2009, p.51), mesmo que não explícitas, foi através das manifestações, movimentos e músicas. Nesta época surgem, por exemplo, os movimentos feministas e estudantis, o rock and roll e ídolos polêmicos por revolucionarem, como Elvis Presley e os Beatles, entre outros. Os jovens rebeldes da geração Baby Boomers violavam as regras estabelecidas e exibiam comportamentos contrários ao padrão da época, como o adultério, a dependência química, manter os cabelos longos e usar roupas justas e marcando o corpo, como formas de protesto ao militarismo e a opressão.

Entretanto, mesmo com comportamentos tão distintos, as duas vertentes de jovens da geração Baby Boomers não se identificavam somente por serem da mesma época, mas também por terem ambições em comum, como a busca por qualidade de vida, a idealização do corpo e o desejo de se manter sempre jovem; independentemente da idade, buscavam continuamente o crescimento e o reconhecimento nas coisas que faziam. Na relação com o trabalho, para a geração Baby Boomers este representou uma "forte expectativa pela gratificação e crescimento pessoal, que pudessem ser alcançados como fruto de suas conquistas" (Oliveira, 2010, p.52). Foram profissionais altamente competitivos e adaptáveis a qualquer organização e viam o companheiro de trabalho como competidor e inimigo, o que lembra a educação que receberam dos pais, por sua vez, herdada dos campos de batalha na guerra. Fazer carreira era seu principal objetivo. Geralmente, eram egocêntricos e ocupam os cargos de maior hierarquia dentro das organizações. E, como lideres, defendiam as teorias motivacionais ligadas aos funcionários e a liderança, com a participação de todos; mas, no geral, não as praticaram. Devido ao crescimento econômico da época, tiveram acesso a uma melhor educação e estímulos, o que lhes permitiu adquirir maior escolaridade e instrução que, acompanhados do cuidado com o corpo e a saúde, fez com que esses profissionais se aposentassem mais tarde, pois gozavam de vitalidade e mantinham o anseio de produzir sempre e movimentar a economia a qualquer custo.

\section{A Geração X}

Segundo Oliveira (2009, p.54), a geração X compreende os nascidos entre 1960 e 1980. Nesta época, os Baby Boomers já se encontravam na fase adulta e tinham a inteira responsabilidade por suas vidas, se rebelandoainda mais em relação as imposições, tornandose altamente questionadores e reivindicadores. Mudou a maneira de lidar com as pessoas, principalmente com a família, o que, segundo Oliveira (2010), reformulou a forma de educar, criar e corrigir os filhos, pertencentes à geração X. Assim, o meio familiar dessa geração sofreu profundas mudanças, pois os jovens passaram a conviver com o divórcio e a ausência dos pais, devido ao trabalho. "A separação tornou-se também um importante instrumento de liberdade de escolha e de busca da felicidade. Ser divorciado deixou de ser algo vulgar e escandaloso nas famílias", e fez com que se desenvolvesse nos jovens "uma atitude mais egocêntrica e cética" (Oliveira,2010,p.56). Os interesses das crianças dessa geração diferiram bastante dos interesses dos seus pais, pois nesse período foi inventado um artefato que marcou a época: a televisão, muito mais interessante do que os brinquedos e jogos característicos das épocas anteriores. Os pais, ao perceberem isso, passam a utilizá-la como uma forma de educar, como base de trocas - um comportamento favorável recebia uma 
recompensa satisfatória; caso contrário, como forma de punição, ficavam sem ver suas programações favoritas, como os desenhos. Esses jovens também viam, nos programas da televisão, através da identificação, formas de manifestação de seus desejos e fantasias, mesmo que inconscientes. A evolução da tecnologia, juntamente com o surgimento de outros eletrônicos e a internet, unidos ao poder das propagandas, influenciou e continua influenciando as gerações. Essas novidades despertaram o consumismo nesses jovens, favorecendo o surgimento de comportamentos como o desejo aguçado de comprar, incentivado pela mídia e pelo meio social.

Partindo das diferenças observadas nos comportamentos e nas características dos jovens pertencentes à geração X, Oliveira (2009, p.57-61) os divide em grupos como: "o revolucionário, o musical, o familiar e o workaholic". O revolucionário "criou um excelente ambiente para manifestar suas insatisfações por meio dos movimentos estudantis, que despontavam em varias partes do mundo"; quando não conseguiam se identificar com os movimentos políticos da época, que ocorriam, em muitos casos com atos de violência, buscavam revolucionar através de manifestações pacíficas, com discursos e movimentos, como os hippies, que protestavam pela "liberdade sexual e dos direitos iguais". O musical, no inicio, se misturava com os revolucionários, expressando, em alguns casos, agressividade e indignação através da música; mas aos poucos foi encontrando, por intermédio desta, uma sensação prazerosa, que lhes possibilitava aumentar sua rede social. A música causava uma sensação de bem estar, diversão e possibilidade de relacionamento informal nas danceterias, proporcionando maior liberdade em suas atitudes. O familiar compreende os jovens que colocavam a família no lugar principal em suas vidas; eram passivos e tolerantes para com os conceitos e valores recebidos de seus pais e não os contestavam - buscavam manter a estabilidade familiar. Já os workaholic, colocavam a família em segundo plano, já que no primeiro plano estava sua carreira profissional. Buscavam o sucesso desde cedo, iniciando no mercado de trabalho de forma precoce e procurando se manter qualificados para serem promovidos e ocuparem cargos de nível hierárquico elevado. Dentro desse grupo surgiu os yuppies, que ficaram conhecidos por "apresentar resultados financeiros alcançados, muitas vezes, colocando em jogo os valores pessoais" (p.60).

A relação da geração $X$ com o trabalho foi influenciada pelo fato de viverem num mundo em constante transformação, onde, por exemplo, a economia passava por um momento de amplificação e o modelo familiar sofria uma nova estruturação. Os jovens dessa geração desenvolveram uma postura mais flexível, criativa e organizada, pois tinham que se adaptar à nova realidade, desenvolvendo também a autonomia. Resende (2008) argumenta que, em geral, os membros dessa geração possuíam, como características: espontaneidade de gestos e atitudes, demonstrando uma postura mais descontraída, preferindo a informalidade; procuravam estar sempre atualizados profissionalmente, pois colocavam o trabalho como prioritário; mas também gostavam de desenvolver atividades que lhes trouxessem sensação de prazer e bem-estar; devido ao consumismo, não se apegavam tanto ao dinheiro, estando mais interessados em ser criativos, apresentar resultados e mostrar sua capacidade e profissionalismo ao longo do tempo, mais do que ter recompensas financeiras imediatas, de curto prazo, não acompanhadas de reconhecimento; e apreciavam a liberdade e a flexibilidade para tomar decisões junto aos chefes e as organizações, não gostando muito de ser controlados. De acordo com Oliveira (2010, p.57), a geração X, "foi uma geração marcada pela autoconfiança em suas escolhas, que buscou promover a igualdade de direitos e de justiça em suas decisões".

\section{A Geração Y}

De acordo com Oliveira (2009), a geração Y compreende os nascidos entre 1980 e 2000 . Atualmente, seus membros mais velhos estão chegando aos 30 anos e, os mais novos, estão na adolescência. Os modelos familiar, econômico e social dessa geração foram os que mais tem sofrido modificações, o que tem feito com que esses jovens sigam modelos bem mais flexíveis. Nessa geração, o modelo familiar, que já vinha se modificando, tornou-se mais dinâmico, onde a possibilidade de separação dos pais revelou-se mais presente, mas não com o impacto que causou na geração anterior, a geração X. Os jovens da geração Y também já estão acostumados, em sua grande maioria, a ver os pais trabalhando, buscando não só o seu próprio crescimento, estabilidade e possibilidade de melhoria, mas também para lhes proporcionar tudo o que não tiveram ou mais. Os pais dessa geração têm dado aos filhos uma educação mais flexível, na qual prevalecem o dialogo e a possibilidade de discussão e negociação, cercada de estímulos e apoio. A geração Y está acostumada a ter todas as suas necessidades atendidas, de forma acelerada. No entanto, não demonstra muita paciência para esperar por coisas de longo prazo, construindo sua realidade de forma que possa obter o que deseja em curto prazo.

A ausência dos pais, devido à dedicação ao trabalho, é revertida em estímulos e recompensas. Entretanto, Oliveira (2009, p.68-69) alerta para a figura do homem "omisso nos referenciais de valores que deveriam ser transmitidos aos filhos"; em contrapartida, a figura da mulher é vista como tentando se fazer presente e suprir a lacuna deixada, de forma a não ser omissa nem 
abandonar seu papel na família. As mulheres procuram oferecer "instrumentos educacionais" que permitem aos filhos se desenvolverem mais rapidamente e serem competitivos, não deixando que a ausência signifique falta de cuidado e carinho - em consequência, essa tem se tornado a geração que mais recebe apoio e estímulos. Para muitos pais, preparar os filhos para o mercado de trabalho é uma missão, pois querem que eles desenvolvam diferenciais que os levem ao sucesso; isso estimula sua competitividade e seu desejo de ser e ter o melhor, buscando sempre estar na frente de outros, o que, em alguns casos, é visto como individualismo por determinados gestores (Oliveira, 2009). Essa geração demonstra maior facilidade em dominar outros idiomas, principalmente o inglês, devido ao acesso à tecnologia e aos estímulos recebidos pelos pais, que reconhecem a importância da fluência em outros idiomas para a carreira profissional dos filhos.

Os jovens da geração Y utilizam uma tecnologia bastante desenvolvida e diversificada, para a obtenção de informações de forma rápida e a resolução de problemas com agilidade, ampliando sua rede de comunicações. Imersos numa era na qual impera a tecnologia, não conhecem outra realidade e não conseguem imaginar o mundo sem ela - isso influencia sobremaneira sua educação e seu comportamento. Conforme Oliveira (2009), nesse momento, a televisão já não desempenha o mesmo papel que na geração $X$, deixando de ter a funcionalidade de ajudar a educar. Esses jovens buscam por algo que lhes permita desenvolvimento e interação, que lhes proporcione estímulos e a possibilidade de participar de forma ativa, optando atividades que não os mantenham passivos, procurando sempre realizar algo. O vídeo game, embora já existente na geração anterior, apresenta agora novas funcionalidades e tornase um dos marcos dessa época, sendo uma das primeiras tecnologias a proporcionar superação de desafios e comparação de resultados, ao lado de competitividade e disputa, promovendo interação com o meio social. A popularização do computador e da internet, que também apareceu nesse período, agrega valor e promove flexibilidade na consecução das tarefas e permite a ampliação de conhecimentos, pois "a informação tornou-se irrestrita e ilimitada: o jovem teria sua fome por conhecimento recompensada na nova tecnologia" (p.72).

Conforme argumenta Oliveira (2009, p.73), "toda diversidade criada a partir de jovens na geração $\mathrm{X}$, associada ao cenário de novas tecnologias $\mathrm{e}$ novas estruturas familiares, permitiu o surgimento de múltiplas categorias e agrupamentos de perfis de jovens, hoje conhecidos como tribos". Dando ênfase a algumas características, classificou as mais relevantes como: alternativos, burgueses, sonoros e urbanos. Os alternativos demonstram certa repulsa frente pessoas contrárias às suas opiniões, podendo mostrar-se agressivos e indiferentes caso não sejam aceitas sua forma de expressão, estilo de vida e posição política, se subdividindo nos "emos, punks e góticos"; essa subdivisão demonstra que as tribos se formam de acordo com afinidades, aceitação e igualdade de interesses. Já o grupo dos burgueses surgiu nas classes sociais com maior poder aquisitivo, podendo usufruir de uma educação ainda mais diferenciada e munida de muitos outros estímulos; para Oliveira $(2009$, p.77), apresentam uma "personalidade que transmite sofisticação e seletividade"; mas, quando não são educados para terem um comportamento ético acompanhado de moralidade, "serão conhecidos por sua superficialidade e indolência"; suas prioridades são focadas em diversão, não possuem muitas responsabilidades e voltam suas ações para algo em que não precisem tomar decisões, mantendo-se ligados aos pais, em alguns casos, por muitos anos, sem preconceitos ou preocupações, pois sua posição lhes permite comodidade; neste grupo temos as seguintes tribos: "os formais ou preppys, os baladeiros e os blogueiros". O grupo dos sonoros consiste nos jovens que fazem dos sons, da música, uma forma de expressão de suas emoções, transmitindo, assim, sua posição em relação à sociedade e a política; nesse grupo, Oliveira (2009) classifica as tribos como: metaleiros/roqueiros, funkeiros, pagodeiros, gospel e outros. E o grupo dos urbanos engloba os jovens residentes nas grandes cidades, que são atraídos por melhores oportunidades, salários e empregos; preferem trabalhar em ambientes com maiores recursos e melhores condições de vida; gostam de praticar esportes e estar conectados às novidades tecnológicas; buscam diversão em lugares que tenham diversidade de entretenimento, optando pelos shoppings; prezam a natureza e adoram viajar.

Para Wada e Carneiro (2010), essa geração é a mais jovem a fazer parte do ambiente de trabalho, possuindo características típicas e predominantes como: o comportamento empreendedor, assinalado pelo desejo de inovação, sem medo de arriscar, que é acompanhado de atitudes criativas, persistentes e visão globalizada perante o futuro. Com muita responsabilidade sobre o que fazem e sempre utilizando ferramentas virtuais como base, os membros da geração $\mathrm{Y}$ conseguem se expressar de forma clara e precisa. Entretanto, quando algumas dessas características se modificam e/ou não funcionam como o estabelecido, podem ser interpretados, por muitas pessoas, principalmente pelos gestores, como "imaturos, inertes, acomodados, com necessidade de orientação" (Wada e Carneiro, 2010, p 2). A geração Y é considerada “(...) uma geração otimista, proativa, ambiciosa, que valoriza o trabalho em equipe e o relacionamento com a liderança e os colaboradores e 'quer fazer a diferença'. É a geração que engloba os filhos "da revolução da informação" (Khoury, 2009, p.125).

Oliveira (2010) reconhece que os membros 
dessa geração possuem diferenciais qualitativos: são capazes de dinamizar as atividades de tal forma que impressionam todos a sua volta. É uma geração que consegue fazer críticas, com uma visão clara de possíveis falhas e alternativas, dispondo do conhecimento necessário adquirido dos seus muitos estímulos. A geração Y consegue estabelecer e seguir metas de forma peculiar, reconhecendo a importância do conhecimento técnico e científico, mantendo-se em constante aprendizagem e buscando novos desafios.

Como os membros dessa geração "dedicam-se a tantas atividades simultâneas, é visível a superficialidade de suas opiniões a respeito se assuntos complexos" (Oliveira, 2009, p.138). Por isso, costumam agir mais do que planejar e não se envolvem com a mesma coisa por muito tempo.

É uma geração que tem a autoestima fortalecida e consegue expressar-se de forma a transmitir seu ponto de vista e seus sentimentos sem temor. Os jovens da geração Y olham as coisas e as pessoas com igualdade, não fazendo distinção e tendo respeito por todos, no sentido de estarem acostumados às diversidades; no entanto, também exigem ser tratados da mesma forma, já que norteiam seu comportamento por este viés, exigindo reciprocidade. Mostram-se contrários aos julgamentos precoces e acreditam que o talento, a habilidade e a competência de cada um 'fala por eles', admirando a competência real e não a hierarquia. Demonstram responsabilidade social, reconhecendo o impacto empresarial sobre a vida das pessoas e, principalmente, sobre o meio ambiente, tendo maior consciência ecológica (Khoury, 2009).

Outros comportamentos que também caracterizam a geração Y, segundo Oliveira (2010, p.64), são: a "necessidade de constante reconhecimento, a opção por padrões informais e flexíveis, a individualidade como forma de expressão e a busca intensa por ampliação da rede social". Os jovens dessa geração gostam de ser reconhecidos e ter retorno sobre o que fazem; são informais no modo como se vestem, preferindo adotar um visual mais despojado, com uso de calças jeans, camisas de malhas etc.; isso fez com que certos paradigmas impostos pelas outras gerações fossem quebrados, como o ato de rotular as pessoas por seu vestuário, como se este definisse suas capacidades e habilidades, "substituindo a valorização da liberdade por flexibilidade e conveniência em seu comportamento" (Oliveira, 2010, p.65). Esses jovens têm se revelado profissionais mais individualistas, no sentido de querer ter seu espaço, uma vez que já estão acostumados a isso no ambiente familiar. Procuram deter maior conhecimento, já que sempre foram estimulados a isso, e seu relacionamento social se dá com o predomínio da tecnologia, “(...) registrando uma tendência em desenvolver o próprio conteúdo para estimular novos relacionamentos" (Oliveira, 2010, p.68).

\section{Dificuldades gerenciais no trato da geração Y no ambiente de trabalho}

No ambiente organizacional, os jovens da geração Y demonstram, em determinados momentos, impaciência, ansiedade e superficialidade, por vezes, sendo transitórios e ambíguos em suas decisões e escolhas (Oliveira, 2010). Esse comportamento impaciente e ansioso pode ser um reflexo do momento em que vivem, cujo marco do progresso mundial é a vida acelerada, com o predomínio da tecnologia munida de soluções lógicas de forma muito rápida, que facilita a dissipação das informações quase instantaneamente, gerando impaciência em relação à espera e criando a ansiedade de que todas as outras coisas ocorram da mesma forma e na mesma velocidade. Além disso, esses jovens mostram-se questionadores, não exatamente no sentido de contestar a postura do líder, conforme visto por alguns gestores, mas pelo desejo de entender melhor o que se passa em determinadas situações, já que possuem visão aguçada para erros e falhas, devido ao seu alto grau de instrução. Procuram interagir e buscar alternativas para alcançar o objetivo proposto; e não vendo os líderes como figuras de autoridade, consideram que podem continuar a fazer o que estavam acostumados no ambiente familiar, ou seja, discutir e argumentar. Não conseguem lidar muito bem com críticas, o que pode ser interpretado por alguns gestores como afronta a sua postura de líder (Wada e Carneiro, 2010). Para Khoury (2009, p.128), 'os membros desse grupo não suportam ser discriminados e tratados com desrespeito pelo fato de serem jovens'.

O modo de pensar dessa geração, conforme observado por Oliveira (2010), é diferente das anteriores e esses jovens não se adaptam aos modelos tradicionalistas, muitas vezes predominantes na gestão de algumas organizações; isso, em muitos casos, se torna motivo de conflito, tendo em vista que existem pessoas de outras gerações, acostumadas com esses modelos, interagindo no mesmo ambiente, o que pode provocar uma grande defasagem entre os profissionais se não for promovida uma adaptação dos jovens que estão chegando. Além disso, no ambiente de trabalho, estes jovens almejam ser promovidos rapidamente e, por isso, se dedicam tanto; querem alcançar o topo da hierarquia, não pelo simples desejo de serem superiores, mas para mostrar que são capazes. É uma geração que não cria fortes vínculos com a instituição e não espera permanecer na mesma por muitos anos, a menos que esta lhes ofereça muitos atrativos; em consequência, a rotatividade tornou mais complexa a tarefa de reter esses jovens talentos.

Nesse contesto, uma vez que eles não formam vínculos concretos com a instituição, nem com a figura do líder, caso esta não atenda suas necessidades ou não 
apresente fortes atrativos, a perda dos jovens talentos pode ocorrer de forma abrangente. Eles podem trocar de empresa com muita facilidade, pois reconhecem seu potencial e não se importam em mudar, podendo até superestimar-se. Assim, se a organização não estiver preparada para lidar com seus diferenciais, isso também pode se transformar numa zona de conflito, podendo provocar, além de desentendimentos, tanto com a organização quanto com seus membros, uma rotatividade muito alta de mão de obra qualificada. Por outro lado, a empresa que atenda as necessidades dos jovens dessa geração, mesmo que parcialmente, lucrará, e muito, porque não há dúvidas de que são altamente promissores e rendáveis às organizações.

\section{Expectativas da geração $Y$ em relação ao trabalho junto às organizações}

Conforme estudos realizados por Oliveira (2010, p.69-70), os jovens da geração Y buscam no ambiente de trabalho:

- Crescimento de carreira - que envolve reconhecimento, melhores posições, estabilidade financeira e emocional e assumir desafios;

- Desenvolvimento profissional - que envolve conhecimento, experiência, aprendizado de novas técnicas, tornar-se mais capacitado e assumir grandes responsabilidades;

- Ambiente de trabalho agradável - que envolve não intimidação, bem-estar, constante criação, respeito e bom relacionamento com os colegas;

- Bons salários e benefícios - que envolve maior responsabilidade, maior salário, salário compatível com o cargo, estabilidade financeira e segurança e reconhecimento pelo que faz;

- Cursos e treinamentos - que envolve crescer junto com a empresa, melhorar as ferramentas para o crescimento e aperfeiçoamento na área de trabalho.

Os jovens dessa geração esperam receber feedback constante sobre o que fazem e recompensas em consequência de seus acertos, já que foram educados dessa forma - desejam sempre saber o que as pessoas pensam a respeito de suas ações (Oliveira, 2010). E quanto à postura dos gestores, tanto Oliveira (2010) quanto Khoury (2009) asseveram que os jovens dessa geração esperam que seus líderes: conheçam o negócio da empresa em amplitude para que possam saber definir prioridades e delegar atividades de acordo com estas; unam os interesses e metas das organizações às suas expectativas e anseios, sendo objetivos e claros; possam desenvolver os profissionais oferecendo treinamento permanente; tenham, em sua essência, uma união de interesses e aplicabilidade de forma rápida; ofereçam feedback conforme suas expectativas; e respeitem e estimulem seus talentos, não os julgando ou discriminando por sua idade, 'tempo de casa' ou preconceitos.

\section{Como trabalhar com a geração $Y$ unida os interesses das empresas}

De acordo com Lombardia et al (2008), o que atrai os jovens da geração $\mathrm{Y}$ às organizações são as vantagens que elas oferecem - hoje não basta somente oferecer emprego e salário, pois os jovens da geração Y também querem melhores condições físicas e mentais, além de oportunidade de lazer e alguns privilégios; exigentes, analisam as ofertas recebidas verificando se estas vão ao encontro das suas expectativas, optando por permanecer na organização mais vantajosa. Isso pode não ser encarado de forma muito satisfatória por algumas organizações que apresentam resistência a mudanças; porém, reconhecem que algo deve ser feito para que não ocorram conflitos e rotatividade de mão de obra, que podem baixar o desempenho de sua produção. Assim, à medida que as empresas oferecem esses benefícios $\mathrm{e}$ recursos - adotando, por exemplo, políticas de Recursos Humanos tais como plano de cargos e carreiras -, elas também podem exigir maiores resultados de seus funcionários, que os cumprirão como forma de se manter nessa condição confortável. Essa circunstância permite unir os interesses do empregado e do empregador, porque as empresas terão funcionários mais focados em suas expectativas e dedicados a cumprir metas e buscando, para isso, todo o conhecimento necessário; isso vai ao encontro do atendimento das necessidades de ambos, mantendo a motivação, já que também traz possibilidades de crescimento e reconhecimento.

De acordo com Silveira e Cohen (2010), outras formas de atrair, reter e gerenciar os profissionais da geração Y são: adotar uma política transparente, onde as pessoas sabem tudo o que se passa em todos os setores, inclusive nas reuniões e os temas discutidos nessas; manter uma remuneração variável, onde se tem um bônus adicional à medida que as coisas são resolvidas e suas metas são alcançadas com atitudes inovadoras; apresentar feedback em tempo real, no qual o jovem possa receber o retorno de suas atividades e desempenho; adotar um programa de retenção de talentos, onde predomina a valorização do trabalho, dando acesso a cargos e posições sociais que se baseiam no mérito pessoal; adotar uma carreira em Y, que dá a mesma possibilidade de crescimento tanto ao nível técnico quanto ao gerencial, onde os funcionários podem escolher seguir uma das duas áreas de atuação e ter recompensas similares; e promover programas de treinamento e desenvolvimento, em que são oferecidos cursos, ministrados dentro e fora das empresas, para o 
desenvolvimento pessoal e profissional.

Os jovens da geração $\mathrm{Y}$ preferem empresas que investem em seus funcionários e confiam no trabalho de seus profissionais, permitindo que tenham autonomia e direitos. Não é apenas o dinheiro que tem valor para eles - almejam se sentir bem no ambiente de trabalho e, por isso, as empresas que não dispõem de um bom capital e não podem pagar salários mais altos, podem adotar essas e outras políticas para atendê-los melhor, visando fazer com que esses funcionários não queiram sair da empresa e se mantenham motivados. Sendo uma geração marcada pelas mudanças constantes do mundo contemporâneo e acostumada a quebrar fronteiras através de suas relações baseadas na tecnologia, um dos fatores de desmotivação é a restrição ao uso da tecnologia, o que pode ser considerado um fator limitador para essa geração, além de não permitir que pratiquem o network, tão necessário nos dias atuais às organizações, como fonte de crescimento e possibilidade de melhoria através da troca com o meio (Oliveira, 2010).

\section{Considerações Finais}

Observamos que, ao longo do tempo, o trabalho passou por várias transformações que fizeram mudar as relações entre empresa e trabalhador, passando a dar ênfase não somente à produção, mas também às relações internas ao ambiente onde se desenvolve, fator que influencia de forma positiva a maneira como as organizações olham para seus funcionários e se torna determinante em seu desempenho. Nesse contexto, o estudo comportamental das gerações presentes no mercado de trabalho permite obter dados que auxiliem e orientem as organizações a adotarem estratégias para atender satisfatoriamente os desejos e necessidades tanto de seus antigos funcionários, quanto dos jovens profissionais que atualmente ingressam nas empresas a geração $\mathrm{Y}$. O primeiro passo nessa direção é estudar seu comportamento, procurando compreender as influências que se exercem sobre essa geração e avaliar $\mathrm{o}$ tem a oferecer, o que proporciona às organizações a oportunidade de melhor adaptar sua gestão. A geração Y precisa da experiência dos profissionais das gerações anteriores que, somada com suas características, poderá resolver os mais diversos problemas presentes nas organizações; portanto, se as empresas souberem como tirar proveito das características de cada uma das gerações conseguirão formar e manter uma melhor força de trabalho, evitando os conflitos que possam surgir entre elas.

A geração $\mathrm{Y}$ tem se mostrado muito habilidosa e talentosa, mas algumas organizações ainda não conseguiram perceber ou desenvolver suas potencialidades, pois ainda mantém modelos de gestão estacionária, ou seja, não acompanharam as modificações proporcionadas por esta geração. É preciso substituir os atuais modelos de gestão, limitados à produção e a seus processos, por modelos baseados em relacionamentos e valorização do potencial humano, promovendo novos desafios que provoquem o crescimento individual.

A soma dos profissionais da geração $Y$, bem qualificados, com as organizações preparadas para seu recebimento, será muito satisfatória para ambos. Os profissionais se sentirão satisfeitos pelo atendimento de suas necessidades, mantendo-se motivados e permanecendo nas empresas; e, por seu turno, as organizações também terão suas expectativas atendidas, pois conseguirão fazer com que esses profissionais se empenhem mais, evitando, assim, a rotatividade da mão de obra especializada, diminuindo seus custos e fortalecendo suas relações recíprocas.

Para conseguir realizar seu trabalho os Gestores precisam da colaboração e conscientização das empresas quanto às necessidades de promover mudanças, pois uma organização que limite seu papel ao recurso técnico, e não dê importância à subjetividade do comportamento humano nas organizações, não conseguirá desenvolver suas potencialidades organizacionais. Ao trabalhar com os membros da geração $\mathrm{Y}$, os Gestores devem entender seus comportamentos e atitudes, para mostrar às organizações todas as vantagens e contribuições que podem trazer para seu desenvolvimento, evitandoreações preconceituosas. Cabe a estes, portanto, manter um ambiente organizacional prazeroso e encontrar políticas que unam os interesses e expectativas das organizações com os de seus funcionários, exercendo o papel de intermediador entre as partes.

\section{Referências}

CHIAVENATO, Idalberto. (2010a) Comportamento organizacional: a dinâmica do sucesso das organizações. 2.ed. Rio de Janeiro: Elsevier.

(2010b) Gestão de pessoas: o novo papel dos recursos humanos nas organizações. 3.ed. Rio de janeiro: Elsevier.

CIENCIA E PROFISSÃO. (2007) Panorama. n.5, p.24-31, Dezembro.

KHOURY, Karim. (2009) Liderança é uma questão de atitude. São Paulo: Senac.

LOMBRADIA, Pilar García; STEIN, Guido; PIN, José Ramón. (2008) Quem é a geração Y. HSM Management, 70, set-out.

MACÊDO, Ivanildo Izaias de; RODRIGUES, Denize Ferreira; JOHANN, Maria Elizabeth Pupe; CUNHA, Neisa Maria Martins da. (2007) Aspectos comportamentais da gestão de pessoas. 9.ed. Rio de Janeiro: FGV.

MACEDO, Kátia Barbosa; CAIXETA, Cássia Maria M.P.; GUIMARAES, Daniela Cristina. (1997) As relações de trabalho na era da globalização. Disponível em: http://www.ucg.br/ site_docente/adm/katia_macedo/pdf/Artigo-HistRelacoes\%20.pdf. Acesso em: 20.out.2010.

NOVO, Damáris Vieira; CHERNICHARO, Edna de Assunção; BARRADAS, Mary Suely. (2008) Liderança de equipes. Rio de Janeiro: FGV.

OLIVEIRA, Sidnei. (2009) Geração Y: era das conexões, tempo dos relacionamentos. São Paulo: Clube de Autores.

(2010) Geração Y: O nascimento de uma nova versão de líderes. 
São Paulo: Integrare.

OLIVEIRA, Silvio Luiz de. (2002) Sociologia das organizaç̃es: uma análise do homem e das empresas no ambiente competitivo. São Paulo: Pioneira.

RESENDE, Enio. (2008) As 4 principais lideranças da sociedade e suas competências. São Paulo: Summus.

SPECTOR, P. E. (2006) Psicologia nas organizações. 2.ed. São Paulo: Saraiva.

SILVEIRA, Mauro; COHEN, David. (2010) O que pensam os presidentes. Revista época, p.82-91, 23.ago.

WADA, Elizabeth Kyoko; CARNEIRO, Natalie Arruda. Necessidades da geração Y no cenário de eventos empresarias. Disponível em: http://www. eumed.net/ce/2010a/kwac.doc. Acesso em: 26.set.2010.

ZANELLI, José Carlos; BORGES-ANDRADE, Jairo Eduardo; BASTOS, Antônio Virgílio Bittencourt. (2004) Psicologia, organizações e trabalho no Brasil. Porto Alegre: Artmed. 